\title{
Assessment of small airway function and reversibility in symptom-controlled asthma in pediatric patients
}

\author{
Rattapon Uppala, ${ }^{1}$ Prapapan Kaenpugdee, ${ }^{1}$ Sureeporn Srisutthikamol, ${ }^{2}$ Jamaree Teeratakulpisarn ${ }^{1}$
}

\begin{abstract}
Background: The goals of asthma management aim to control the symptoms and minimize future risk. There is, however, an option to stop controller medication if the patient has been well-controlled for at least 6-12 months. To assess control, both clinical symptom assessment and lung function should be monitored periodically. In practical clinical practice of pediatric patients, lung function is not available at all health centers.
\end{abstract}

Objectives: to determine lung function with a focus on small airway function and the risk of reversibility among children who have been symptom-controlled.

Methods: Our participants were symptom-controlled asthmatic children according to GINA Guideline for at least 6 months with low dose inhaled corticosteroid. Written informed-consent was given by the parents and the children. They performed a self-evaluated symptom-controlled test (C-ACT) and a spirometric assessment. Abnormal lung function was defined as $\mathrm{FEV}_{1}<80 \%, \mathrm{FEV}_{1} / \mathrm{FVC}<80 \%$, and $\mathrm{FEF}_{25-75}<65 \%$ predicted. Airway reversibility was determined by the change of $\mathrm{FEV}_{1}>12 \%$ and $\mathrm{FEF}_{25-75}>30 \%$ post bronchodilator.

Results: Forty children (65\% male) were enrolled. Age ranged between 6.7 and 15.0 years. The mean C-ACT score was 25.2 \pm 1.7. Spirometry results were: mean $\mathrm{FEV}_{1} 84.0 \% \mathrm{FEV}_{1} / \mathrm{FVC} 87.8 \%$, and $\mathrm{FEF}_{25-75} 85.5 \%$ predicted. Normal FEV ${ }_{1}$ was found among $72.5 \%$ of participants compared to normal $\mathrm{FEF}_{25-75}$ in $87.5 \%$. Among the abnormal $\mathrm{FEV}_{1}$ and $\mathrm{FEF}_{25-75}$, all were of mild severity as $10 \%$ retained airway reversibility.

Conclusion: Children with well-controlled asthma, based on their symptom assessment, may have persistent abnormal lung function. Spirometry should be performed before considering cessation of controller medication.

Keywords: small airway function, symptom-controlled, asthma, pediatric, spirometry

\section{From:}

${ }^{1}$ Department of Pediatrics,

${ }^{2}$ Division of Nursing, Srinagarind Hospital, Faculty of Medicine, Khon Kaen University, Khon Kaen, Thailand
Corresponding author:

Jamaree Teeratakulpisarn

Department of Pediatrics, Faculty of Medicine,

Khon Kaen University, Khon Kaen, 40002, Thailand

Email: jamtee@kku.ac.th

\section{Introduction}

According to the terms of the Global Initiative for Asthma, the long-term goals for asthma management are to achieve good symptom control, and to minimize future risk of exacerbations, fixed airflow limitation, and side-effects of treatment. Symptom control is assessed using the frequency of daytime \& night-time asthma symptoms, reliever use, and activity limitation. Poor symptom control is a risk factor for future exacerbations. Lung function, which mainly focuses on $\mathrm{FEV}_{1}$ and the $\mathrm{FEV}_{1} / \mathrm{FVC}$ ratio, should be assessed as an indicator of future risk. ${ }^{1}$

It is well-established that inflammation in asthma involves not only the large airways, but also the small airways; the complete airway tree. ${ }^{2-3}$ Small airway inflammation is recognized as having an important role in controlling asthma. Increasing evidence suggests that small-airway dysfunction is associated with the clinical features of asthma: such as poor control of asthma and higher numbers of exacerbations. ${ }^{4}$ In addition, significant bronchodilator reversibility in a patient taking controller treatment also suggests uncontrolled asthma. ${ }^{1}$

When asthma is well-controlled, complete cessation of inhaled corticosteroids (ICS) in adults is not advised as the risk of exacerbations is increased. ${ }^{1,5}$ Nevertheless, a physician may consider stopping controller treatment only if there have 
been no symptoms for 6-12 months and the patient has no risk factors. ${ }^{1}$ By comparison, in clinical pediatric practice, routine lung function at each visit is difficult to perform. Moreover, spirometry is not available at all health care centers in our country (Thailand), so assessment of asthma symptom control is accomplished for reviewing the treatment and controller cessation. Even if children have clinical symptom control, the future risk of exacerbations and lung function (especially of the small airways) are unknown. We, thus, conducted the current study to determine lung function with a focus on small airway function as well as the risk of reversibility among children who have been assessed as symptom-controlled.

\section{Methods}

We conducted a prospective, descriptive study in children diagnosed with asthma according to the GINA guideline, and who regularly attended the Pediatric Asthma Clinic at Srinagarind Hospital, Khon Kaen University, between August 2015 and August 2016. At each visit, the patients were assessed for symptoms and those who met the criteria for symptom -controlled were invited to participate in the study. This study was approved by the Ethics Committee for Human Research of Khon Kean University, Thailand (HE581314)

\section{Study populations}

The enrolled asthmatic children were: 1) between 6 and 15 years of age and regularly attended the clinic; 2) symptom -controlled for at least 6 months [as per the GINA 2015 clinical assessment]; 3) regularly used low-dose inhaled controllers (Budesonide $\leq 200 \mu \mathrm{g} /$ day or Fluticasone $\leq 200 \mu \mathrm{g} /$ day plus LABA) ${ }^{1}$; and, 4) able to perform spirometry. Each child participant had informed, written parental consent as well as giving their own assent. Children who had had a respiratory infection in the previous 1 month and had a history of using bronchodilator before performing spirometry within 6 hours were excluded. The symptom control score for the last 1-month of symptoms was determined using the childhood asthma control test (C-ACT). ${ }^{6}$ Parents and children who met all the eligibility criteria were asked to perform the C-ACT test before performing spirometry.

Symptom-controlled (GINA clinical assessment) ${ }^{1}$ was defined as exhibiting none of the following: daytime symptoms more than twice/week; any night waking due to asthma; any reliever needed for symptoms more than twice/week; and, any activity limitation due to asthma in the past 4 weeks.

Childhood asthma control test (C-ACT) ${ }^{6}$ is a seven-item assessment questionnaire, completed by the child and parent/ caregiver, for assessing asthma control in children between 4 and 11 years of age in the preceding four weeks: the total score ranges between 0 and 27. The C-ACT test has been translated into Thai; however, it has not been validated in Thai children.

\section{Pulmonary and small airway function}

Lung function was measured using a CHEST multifunctional spirometer $\mathrm{HI}$ - 801. Typical $\mathrm{FEV}_{1}$ and $\mathrm{FEV}_{1} / \mathrm{FVC}$ were evaluated to determine large airway function, and $\mathrm{FEF}_{25-75}$ the latter reflecting small airway function. Repeated spirometry was performed 15 minutes after giving inhaled Ventolin Evohaler ${ }^{\oplus}$ plus spacer to determine reversibility of the airway. Abnormal lung function was defined as $\mathrm{FEV}_{1}<80 \%$ predicted, $\mathrm{FEV}_{1} / \mathrm{FVC}<80 \%$, and $\mathrm{FEF}_{25-75}<65 \%$. Post bronchodilator, the change of $\mathrm{FEV}_{1}>12 \%$ and $\mathrm{FEF}_{25-75}>30 \%$, was positive for reversibility. ${ }^{7-8}$ Spirometry was performed by the same trained nurse throughout the study. We documented the demographic characteristics, BMI, family history of atopy, co-morbidity, time of asthma diagnosis, and treatment.

\section{Study analysis}

Statistical analyses were performed using SPSS version 19 . Continuous data were presented as means $\pm \mathrm{SD}$, medians, and ranges (minimum to maximum). Categorical data were presented as numbers and percentages of each group.

\section{Results}

There were 40 patients who met the eligibility criteria. There were $26(65 \%)$ males and overall the age ranged between 6.7 and 15.0 years (mean, 10.4 \pm 2.0 ). BMI ranged between 12.4 and 27.2 (mean, $18.3 \pm 3.8 \mathrm{~kg} / \mathrm{m}^{2}$ ). No child was diagnosed as obese (i.e., $\mathrm{BMI} \geq 95^{\text {th }}$ percentile). Half of the patients had a co-morbidity with the allergic rhinitis. Sixteen (40\%) had a family history of smoking by the father and/or grandfather. Other baseline characteristics included mean duration of diagnosed asthma $(6.0 \pm 3.2$ years) and mean duration of taking ICS $(5.6 \pm 3.3$ years). Half of the patients had had a history of admission due to asthma exacerbation prior to being symptom-controlled (average, 2 times). (Table 1) No child had severe exacerbation

Table 1. Demographic characteristics of the studied population

\begin{tabular}{|l|r|}
\hline Characteristic & Total N = 40 \\
\hline Sex, male (\%) & $26(65.0)$ \\
\hline $\begin{array}{l}\text { Age, (years) } \\
\text { mean } \pm \text { SD } \\
\text { median (min - max) }\end{array}$ & $10.4 \pm 2.0$ \\
\hline $\begin{array}{l}\text { BMI, (kg/m }{ }^{2} \text { ) } \\
\text { mean } \pm \text { SD } \\
\text { median (min - max) }\end{array}$ & $10.4(6.7-15.0)$ \\
\hline $\begin{array}{l}\text { Birth weight, (g) } \\
\text { mean } \pm \text { SD } \\
\text { median (min - max) }\end{array}$ & $18.3 \pm 3.8$ \\
\hline $\begin{array}{l}\text { Breastfeeding, (months) } \\
\text { mean } \pm \text { SD } \\
\text { median (min - max) }\end{array}$ & $3,160.6 \pm 337.7$ \\
\hline Family history of smoking, $\mathrm{n}(\%)$ & $3.17 .27 .7)$ \\
\hline History of allergic rhinitis, $\mathrm{n}(\%)$ & $3.0(1-8)$ \\
\hline $\begin{array}{l}\text { History of admission prior to } \\
\text { symptom-controlled, } \mathrm{n}(\%)\end{array}$ & $16(40.0)$ \\
\hline mean number of admissions & $20(50.0)$ \\
\hline median (min - max) & $20(50.0)$ \\
\hline $\begin{array}{l}\text { History of severe exacerbation or admission in } \\
\text { the past year }\end{array}$ & $2.1 \pm 1.8$ \\
\hline
\end{tabular}


or admission during the past year. The mean C-ACT score was 25.2 \pm 1 .7. The range of C-ACT for most children was 22 to 27 . Only one child had a score as low as 19 . Additional diagnoses and treatment are shown in Table 2.

Lung function outcomes were: mean of predicted $\mathrm{FEV}_{1}$ $84.0 \pm 8.1 \%, \mathrm{FEV}_{1} / \mathrm{FVC} 87.8 \pm 6.1 \%$, and $\mathrm{FEF}_{25-75}$ predicted $85.5 \pm 20.0 \%$. Normal large airway function $\left(\mathrm{FEV}_{1} \geq 80 \%\right)$ was found in only $72.5 \%$ of participants while normal small airway function $\left(\mathrm{FEF}_{25-75} \geq 65 \%\right)$ was found in $87.5 \%$. Among the abnormal $\mathrm{FEV}_{1}$ and $\mathrm{FEF}_{25-75}$, all were of mild severity $\left(\mathrm{FEV}_{1}>\right.$

Table 2. Treatment and symptom control of asthma prior to enrollment

\begin{tabular}{|c|c|}
\hline Disease characteristic & \\
\hline $\begin{array}{l}\text { Onset of suspected asthma symptoms (years) } \\
\text { mean } \pm \text { SD } \\
\text { median (min - max) }\end{array}$ & $\begin{array}{r}3.5 \pm 3.2 \\
2.0(0.1-12.0)\end{array}$ \\
\hline $\begin{array}{l}\text { Age at asthma diagnosis (years) } \\
\text { mean } \pm \mathrm{SD} \\
\text { median ( } \min -\max )\end{array}$ & $\begin{array}{r}4.3 \pm 3.2 \\
4.0(0.8-12.0)\end{array}$ \\
\hline $\begin{array}{l}\text { Duration of asthma (years) } \\
\text { mean } \pm \text { SD } \\
\text { median (min - max) }\end{array}$ & $\begin{array}{r}6.0 \pm 3.2 \\
5.8(0.8-11.2)\end{array}$ \\
\hline $\begin{array}{l}\text { Duration of taking ICS (years) } \\
\text { mean } \pm \text { SD } \\
\text { median }(\min -\max )\end{array}$ & $\begin{array}{r}5.6 \pm 3.3 \\
5.1(0.8-11.2)\end{array}$ \\
\hline $\begin{array}{l}\text { Duration of controlled symptoms (years) } \\
\text { mean } \pm \text { SD } \\
\text { median (min - max })\end{array}$ & $\begin{array}{r}1.7 \pm 2.3 \\
1.0(0.5-10.0)\end{array}$ \\
\hline $\begin{array}{l}\text { Maximum daily dose of controller prior to } \\
\text { symptom-controlled, } \mathrm{n}(\%) \\
\text { Budesonide }>400 \mu \mathrm{g} / \text { day or Fluticasone }>250 \\
\mu \mathrm{g} / \text { day }+\mathrm{LABA} \\
\text { Budesonide } \leq 400 \mu \mathrm{g} / \text { day or Fluticasone } \leq 250 \\
\mu \mathrm{g} / \text { day }+\mathrm{LABA}\end{array}$ & $\begin{array}{l}27(67.5) \\
13(32.5)\end{array}$ \\
\hline $\begin{array}{l}\text { C-ACT score } \\
\text { mean } \pm \text { SD } \\
\text { median }(\min -\max )\end{array}$ & $\begin{array}{r}25.2 \pm 1.7 \\
25.0(19-27)\end{array}$ \\
\hline
\end{tabular}

$70 \%$ predicted) (Table 4). All children who had an abnormal $\mathrm{FEV}_{1}$ and $\mathrm{FEF}_{25-75}$ had a C-ACT score between 22 and 27.

The post-bronchodilator results showed airway reversibility as follows: $\mathrm{FEV}_{1}$ returned to a normal predicted level in 34 patients (85\%) while most of the abnormal $\mathrm{FEF}_{25-75}$ returned to a normal predicted level in 39 patients (97.5\%). Among the children with normal lung function, 4 (10\%) showed airway reversibility: 2 had both large airway $\left(\mathrm{FEV}_{1}>12 \%\right)$ and small airway reversibility $\left(\mathrm{FEF}_{25-75}>30 \%\right)$ and another 2 had only small airway reversibility $\left(\mathrm{FEF}_{25-75}>30 \%\right)$. (Table 5) The clinical characteristic of these 4 children are presented in Table 3. As for the risk of exacerbation, two had allergic rhinitis as co-morbidities with a history of smoking in the family. Three of them received the maximum dose of ICS at a medium level

\section{Table 4. Spirometric results}

\begin{tabular}{|c|c|c|}
\hline Spirometric results & Pre BD & Post BD \\
\hline $\begin{array}{l}\mathrm{FEV}_{1} \\
\quad \text { Mean } \pm \mathrm{SD} \\
\quad \text { Median }(\min -\max ) \\
\quad \geq 80 \%(\text { normal }), \mathrm{n}(\%)\end{array}$ & $\begin{array}{c}84.0 \pm 8.1 \\
84.3(69.1-108.1) \\
29(72.5)\end{array}$ & $\begin{array}{c}86.5 \pm 8.6 \\
85.9(61.2-105.9) \\
34(85)\end{array}$ \\
\hline $\begin{array}{l}\mathrm{FEV}_{1} / \mathrm{FVC} \\
\quad \text { Mean } \pm \mathrm{SD} \\
\quad \text { Median }(\min -\max ) \\
\quad \geq 80 \%(\text { normal }), \mathrm{n}(\%)\end{array}$ & $\begin{array}{c}87.8 \pm 6.1 \\
87.7(71.4-100) \\
37(92.5)\end{array}$ & $\begin{array}{c}90.6 \pm 5.4 \\
91.2(76.4-100) \\
38(95)\end{array}$ \\
\hline $\begin{array}{l}\mathrm{FEF}_{25-75} \\
\quad \text { Mean } \pm \mathrm{SD} \\
\quad \text { Median }(\min -\max ) \\
\quad \geq 65 \%(\text { normal }), \mathrm{n}(\%)\end{array}$ & $\begin{array}{c}85.5 \pm 20.0 \\
83.2(46.8-152.2) \\
35(87.5)\end{array}$ & $\begin{array}{c}99.7 \pm 21.9 \\
96.4(58.1-162.9) \\
39(97.5)\end{array}$ \\
\hline
\end{tabular}

Table 5. Post bronchodilator spirometric results

\begin{tabular}{|c|c|c|c|c|}
\hline $\begin{array}{c}\text { Lung } \\
\text { function }\end{array}$ & FEV $_{1}$ & $\begin{array}{c}\text { Reversible } \\
\text { N (\%) }\end{array}$ & FEF $_{25-75}$ & $\begin{array}{c}\text { Reversible } \\
\text { N (\%) }\end{array}$ \\
\hline $\begin{array}{c}\text { Normal } \\
\text { N (\%) }\end{array}$ & $29(72.5)$ & $2(5)$ & $35(87.5)$ & $4(10)$ \\
\hline $\begin{array}{c}\text { Abnormal } \\
\text { N (\%) }\end{array}$ & $11(27.5)$ & 0 & $5(12.5)$ & 0 \\
\hline
\end{tabular}

Table 3. Clinical characteristics of the subjects who had airway reversibility

\begin{tabular}{|c|c|c|c|c|}
\hline Characteristic & Subject 1 & Subject 2 & Subject 3 & Subject 4 \\
\hline $\mathrm{FEV}_{1}$ reversibility ( $\%$ change $>12 \%$ ) & Yes & No & Yes & No \\
\hline $\mathrm{FEF}_{25-75}$ reversibility ( $\%$ change $>30 \%$ ) & Yes & Yes & Yes & Yes \\
\hline Age of asthma onset (year) & 0.8 & 5 & 1.4 & 7 \\
\hline BMI $\left(\mathrm{kg} / \mathrm{m}^{2}\right)$ & 16.6 & 21.1 & 13.3 & 17.6 \\
\hline Co-morbidity & No & Allergic rhinitis & No & Allergic rhinitis \\
\hline Family history of asthma in $1^{\text {st }}$ degree relative & No & No & No & No \\
\hline Passive smoker & Yes & No & Yes & No \\
\hline History of severe exacerbation in the past year & No & No & No & No \\
\hline Type of controller to achieve asthma control & $\begin{array}{c}\text { Fluticasone + } \\
\text { LABA }\end{array}$ & $\begin{array}{c}\text { Fluticasone + } \\
\text { LABA }\end{array}$ & $\begin{array}{c}\text { Fluticasone + } \\
\text { LABA }\end{array}$ & Budesonide \\
\hline Maximum dose of controller needed to achieve asthma control ( $\mu \mathrm{g} /$ day) & 500 & 250 & 500 & 400 \\
\hline C-ACT score & 26 & 22 & 26 & 25 \\
\hline
\end{tabular}


but none experienced a severe exacerbation or admission in the past year nor were they activity-limited. All of them achieved asthma-control and the ICS could be stepped down to a low dose for more than 6 months, as required before enrollment.

In the abnormal lung function group, none showed any airway reversibility. One child had both mild fixed abnormal $\mathrm{FEV}_{1}$ and $\mathrm{FEF}_{25-75^{\circ}}$ (Pre \& Post BD FEV $=71.4 \& 75 \%, \mathrm{FEF}_{25-75}$ $=46.8 \& 58 \%$ predicted, respectively). The child had a BMI of $27.3 \mathrm{~kg} / \mathrm{m}^{2}$ and had been diagnosed with asthma at 5 . He had been on ICS for 5 years without any severe exacerbation, but was a passive smoker from his father since birth and his C-ACT score was 26.

\section{Discussion}

This study was conducted to test the hypothesis that all asthmatic children who have achieved symptom controlled with low-dose ICS for at least 6 months have normal lung function of the entire airway but in particular of the small airway. As for asthma management, all of the patients not only have to achieve good symptom control, the future risk of exacerbations should be minimal. One of the important future risks is low $\mathrm{FEV}_{1}$. In addition, significant bronchodilator reversibility in a patient taking controller treatment suggests uncontrolled asthma. ${ }^{1}$ The current study showed that some children who were supposed to be well-controlled according to their symptom assessment, continued to have both abnormal large and small airway function.

Several studies have been conducted to determine the correlation of symptom assessment and lung function during the treatment follow-up period. Munoz et al. demonstrated that eosinophilic or neutrophilic inflammation persisted in most well-controlled asthma patients despite their condition being controlled. ${ }^{9}$ Recent studies, moreover, showed that small airway dysfunction is not only a feature of severe asthma but can also present in patients with mild asthma who have a low level of symptoms and normal $\mathrm{FEV}_{1}$ values. ${ }^{10-13}$ Huang et al. demonstrated that the majority of children with well-controlled asthma continued to have airway hyper-responsiveness and low small airway function as represented by $\mathrm{FEF}_{25-75^{\circ}}{ }^{14}$

Many physiological and imaging techniques have been used to evaluate small airway function, including impulse oscillometry, exhaled nitric oxide, inert gas washout, high resolution computed tomography, and spirometry. ${ }^{15}$ Spirometry is often readily available and used most frequently in routine clinical practice. Forced expiratory volume in one second $\left(\mathrm{FEV}_{1}\right)$ and $\mathrm{FEV}_{1} /$ forced vital capacity (FVC) mainly represent the larger airways, whereas forced expiratory flow between $25 \%$ and $75 \%$ of forced vital capacity $\left(\mathrm{FEF}_{25-75}\right)$ reflects small airway function. ${ }^{15}$ Rao et al showed that asthmatic children who had a low $\mathrm{FEF}_{25-75}$ had nearly 3 times the odds (OR 2.8) of systemic corticosteroid use and 6 times the odds of asthma exacerbations (OR 6.3) compared with those who had normal spirometry. In addition, they also concluded that using the percent change in $\mathrm{FEF}_{25-75}$ may be helpful in identifying bronchodilator responsiveness in asthmatic children with a normal $\mathrm{FEV}_{1}{ }^{8}$ Due to our limited resources, we used spirometric results $\left(\mathrm{FEF}_{25-75}\right.$ predicted) to represent small airway function and pre-post bronchodilator values to determine airway hyper -reactivity. We found that $\mathrm{FEF}_{25-75}$ did not add more useful information for the detection of abnormal lung function. Nevertheless, among children who had a normal $\mathrm{FEV}_{1}$, four (10\%) continued to have airway reversibility especially of the small airway. Prior to being considered symptom-controlled, these four children were treated with ICS at a medium dose level. Regarding clinical assessment of future risk of exacerbation, they did not have any striking history, such as a history of severe exacerbation during the preceding year, no activity limitations or C-ACT score between 22-26. Two children had allergic rhinitis as a co-morbidity and environmental smoking exposure. Notwithstanding these clinical characteristics, they were similar to children with normal lung function. The finding of significant bronchodilator reversibility (i.e., an increase in $\left.\mathrm{FEV}_{1}>12 \%, \mathrm{FEF}_{25-75}>30 \%\right)^{16}$ in a patient taking controller treatment suggests persistent uncontrolled asthma, which should be regarded as evidence for further continuing treatment. ${ }^{1}$ Early controller cessation in these patients might lead to severe exacerbation and fixed airway obstruction in the future. This study confirmed the usefulness of assessment of small airway reversibility to determine asthma control status in children. ${ }^{8,16}$

The recent international practice guideline for asthma recommends that lung function-especially spirometry-is a useful indicator of exacerbation, so it should be monitored together with clinical assessment at the start of treatment, after 3-6 months of controller treatment, and periodically going forward. ${ }^{17-18}$ Monitoring asthma management in children according to these guidelines is challenging. In general, symptom control assessment as provided by GINA is used routinely for control-based asthma management at most healthcare centers in our country. Nevertheless, several asthma control scores for children-i.e., Chilhood Asthma Control Test (C-ACT) - have been developed to help in clinical assessment. ${ }^{6}$ Medication adjustment as well as cessation of controller mainly depended on subjective symptom control assessments. The current study used the GINA assessment at the level of well -controlled as indicating symptom control. ${ }^{1}$ We also compared the GINA assessment with the C-ACT score and found that most children who were well-controlled had a C-ACT score in the range of 22 to 27. Only one child whose lung function (both $\mathrm{FEV}_{1}$ and $\mathrm{FEF}_{25-75}$ ) was normal had a C-ACT score of 19. The results of our study on symptom-control assessment are similar to the study by Koolen et al. who showed that a C-ACT score correlated well with the GINA criteria and that children who were well-controlled had a C-ACT score in the range of 23 to $27 .{ }^{19}$ By comparison, Ito et al. showed that a C-ACT cut-off score of 23 was useful for identifying children with well -controlled asthma (sensitivity 78\%; specificity 54\%). ${ }^{20}$ This C-ACT score has been translated into Thai but is not widely used possibly because it has not yet been validated.

The European Task Force recommends performing spirometry annually as a minimum, when monitoring asthma in children. ${ }^{18}$ The results of our study confirmed the usefulness of objective monitoring in asthma patients especially spirometry; however, in our country, spirometry is not available at all levels of health care. The current study demonstrated that even if the clinical assessment (either GINA or C-ACT score) of asthmatic children indicates symptom controlled', their lung function might not be normal and they may even have airway reversibility. We, therefore, suggest that before 
considering cessation of controller medication in children over 6 with well-controlled asthma, a lung function test be performed to demonstrate the actual status, if available.

The limitations of this study were that (a) symptom control assessments were done by several pediatricians caring for the patients, so there will be some variation in assessments; (b) no inter-rater variation was performed before enrollment; and (c) we had a small sample size. In addition, it was a cross-sectional study that might not be able to determine the exact future clinical outcomes. Further study with an adequate sample size and long term cohort should be performed to add more evidence to support the clinical practice guideline.

\section{Conclusion}

The current study demonstrated that asthmatic children, who are considered symptom-controlled based on an assessment of their treatment and symptoms, may still have abnormal lung function. Spirometry should be performed before considering cessation of controller medication.

\section{Acknowledgements}

The authors thank Faculty of Medicine, Khon Kaen University, Thailand for funding support and Mr. Bryan Roderick Hamman for assistance with the English-language presentation of the manuscript.

\section{References}

1. Global Initiative for Asthma Executive Committee. Global Strategy for Asthma Diagnosis and Prevention Updated 2015[Internet]. [Place unknown]: Global Initiative for Asthma; c2015 [cited 2015 Jun 1]. Available from: www.ginasthma.org

2. Hamid Q. Pathogenesis of small airways in asthma. Respiration. 2012;84: 4-11.

3. Hamid Q, Song Y, Kotsimbos TC, Minshall E, Bai TR, Hegele RG, et al. Inflammation of small airways in asthma. J Allergy Clin Immunol. 1997; 100:44-51.

4. van der Wiel E, ten Hacken NH, Postma DS, van den Berge M. Small -airways dysfunction associates with respiratory symptoms and clinical features of asthma: a systematic review. J Allergy Clin Immunol. 2013; 131:646-57.
5. Rank MA, Hagan JB, Park MA, Podjasek JC, Samant SA, Volcheck GW, et al. The risk of asthma exacerbation after stopping low-dose inhaled corticosteroids: a systematic review and meta-analysis of randomized controlled trials. J Allergy Clin Immunol. 2013;131:724-9.

6. Liu AH, Zeiger R, Sorkness C, Mahr T, Ostrom N, Burgess S, et al. Development and cross-sectional validation of the Childhood Asthma Control Test. J Allergy Clin Immunol. 2007;119:817-25.

7. Jat KR. Spirometry in children. Prim Care Respir J. 2013;22:221-9.

8. Rao DR, Gaffin JM, Baxi SN, Sheehan WJ, Hoffman EB, Phipatanakul $\mathrm{W}$. The utility of forced expiratory flow between $25 \%$ and $75 \%$ of vital capacity in predicting childhood asthma morbidity and severity. J Asthma. 2012;49:586-92.

9. Muñoz X, Sanchez-Vidaurre S, Roca O, Torres F, Morell F, Cruz MJ. Bronchial inflammation and hyperresponsiveness in well controlled asthma. Clin Exp Allergy. 2012;42:1321-8.

10. Takeda T, Oga T, Niimi A, Matsumoto H, Ito I, Yamaguchi $M$, et al. Relationship between small airway function and health status, dyspnea and disease control in asthma. Respiration. 2010;80:120-6.

11. Drewek R, Garber E, Stanclik S, Simpson P, Nugent M, Gershan W. The FEF25- 75 and its decline as a predictor of methacholine responsiveness in children. J Asthma. 2009;46:375-81.

12. Fonseca-Guedes $\mathrm{CH}$, Cabral AL, Martins MA. Exercise-induced bronchospasm in children: comparison of FEV1 and FEF25-75\% responses. Pediatr Pulmonol. 2003;36:49-54.

13. Singer F, Abbas C, Yammine S, Casaulta C, Frey U, Latzin P. Abnormal small airways function in children with mild asthma. Chest. 2014;145: 492-9.

14. Huang J, Zhang M, Zhang X, Wang L. Airway hyper-responsiveness and small airway function in children with well controlled asthma. Pediatr Res. 2015;77:819-22.

15. McNulty W, Usmani O. Techniques of assessing small airways dysfunction. Eur Clinical Respiratory J. 2014;1:10.3402/ecrj.v1.25898.

16. Pellegrino R, Viegi G, Brusasco V, Crapo RO, Burgos F, Casaburi R, et al. Interpretative strategies for lung function tests. Eur Respir J. 2005;26: 948-68.

17. Global Initiative for Asthma Executive Committee. Global Strategy for Asthma Diagnosis and Prevention Updated 2016[Internet]. [Place unknown]: Global Initiative for Asthma; c2016 [cited 2016 Dec 3]. Available from: www.ginasthma.org

18. Pijnenburg MW, Baraldi E, Brand PLP, Carlsen KH, Eber E, Frischer T, et al. Monitoring asthma in children. Task Force Report. ERS Statement. ERJ Express. 2015. Eur Respir J. 2015;45:906-25.

19. Koolen BB, Pijnenburg MWH, Brackel HJL, Landstra AM, van den Berg NJ, Merkus PJFM, et al. Comparing Global Initiative for Asthma (GINA) criteria with the Childhood Asthma Control Test (C-ACT) and Asthma Control Test (ACT). Eur Respir J. 2011;38:561-6.

20. Ito Y, Adachi Y, Itazawa T, Okabe Y, Adachi YS, Higuchi O, et al. Association between the results of the childhood asthma control test and objective parameters in asthmatic children. J Asthma. 2011;48:1076-80. 